\title{
Jaw Osteonecrosis a Risk Factor in Bisphosphonate Therapy - A Dental Concern
}

\author{
Manpreet S Walia, Saryu Arora, Bhawana Singal
}

\section{ABSTRACT}

Bisphosphonates are compound used in the treatment of many skeletal disorders such as bone metastases, osteoporosis, Paget's disease, bypercalcaemia of malignancy and bone pain. A new complication of bisphosphonate therapy administration i.e. osteonecrosis of jaw also known as bisphosphonate related osteonecrosis of the jaws seems to be developing. Over suppression of bone turn over is probably the primary mechanism for the development of this condition, although there may be contributing comorbid factors. Complete prevention of this complication is not currently possible. However, preventive dental care reduces this incidence. Conservative debridement of necrotic bone, pain control, infection management, use of antimicrobial oral rinses and withdrawal of bisphosphonates are preferable to aggressive surgical measures for treating this condition.

\section{KEY-WORDS}

Bisphosphonate, Osteonecrosis, Osteoporosis 


\section{INTRODUCTION}

Bisphosphonates are a class of pharmaceutical agents used to treat numerous bone disorders, including osteoporosis, cancer metastases to bone and multiple myeloma(1). Little is known about the side effects and dangers of the long-term use of therapeutic doses of Bisphosphonates. There have been reports on gastrointestinal complications such as gastric and oesophageal erosions and ulcerations and cases of renal failure and acute tubular necrosis. A new complication of bisphosphonates therapy administration, i.e. osteonecrosis of jaws also known as Bisphosphonates associated osteonecrosis (BRONJ) of the jaws, seems to be developing(2). 'Osteo' means bone and 'necrosis' means cell or tissue death. So in simple terms, osteonecrosis (pronounced oss-tee-oh-neh-kro-sis), means death of bone tissue. Bone can die in any part of the body if its blood supply is cut off and the cells can't get oxygen or food(3).

\section{ACTIONS OF BISPHOSPHONATES}

Bisphosphonates are powerful inhibitors of osteoclastic activity. They are analogues of inorganic pyrophosphates with low intestinal absorption, are excreted through the kidneys without metabolic alteration, and have a high affinity for hydroxyapatite crystals $(4,5)$. Because they are incorporated into the skeleton without being degraded, they are remarkably persistent drugs; the estimated half-life for alendronate is up to 12 years(6). Alendronate, risedronate, pamidronate, zoledronic acid, andibandronate, which are called aminobisphosphonates, have much higher potency because they contain nitrogen in a side chain (Table 1). The nonaminobisphosphonates are metabolized by osteoclasts to inactive nonhydrolyzable adenosine triphosphate analogues that are directly cytotoxic to the cell and induce apoptosis $(4,5)$. The newer aminobisphosphonates have two actions(4), induction of another adenosine triphosphate analogue that induces apoptosis, and inhibition of farnesyl diphosphonate synthase, which is part of the mevalonate pathway of cholesterol synthesis. Such inhibition results in dysregulation of intracellular transport, cytoskeletal organization, and cell proliferation, leading to inhibition of osteoclast function. In addition, aminobisphosphonates reduce

\begin{tabular}{|c|c|c|c|c|}
\hline Generic Name & Brand Name & Manufacturer and Location & Dosage Forms & Nitrogen- Containing \\
\hline Etidronate disodium & Didronel & $\begin{array}{l}\text { Procter and Gamble Pharmaceuticals, } \\
\text { Cincinnati, Ohio }\end{array}$ & 200- and 400- mg tablets & No \\
\hline Clodronate disodium & $\begin{array}{l}\text { Bonefos } \\
\text { (Canada) }\end{array}$ & Schering AG, Berlin, Germany & $\begin{array}{l}\text { 400- and 800-mg tables: } \\
60 \mathrm{mg} / \mathrm{mt} . \text { ampule } †\end{array}$ & No \\
\hline Tiludronate disodium & Skelid & $\begin{array}{l}\text { Sanofi-Synthelabo inc., } \\
\text { New York, New York }\end{array}$ & 200-mg tablet & No: Sulfur moiety \\
\hline Alendronate sodium & Fosamax & $\begin{array}{l}\text { Merck and Co. Inc., Whitehouse } \\
\text { Station, New Jersey. }\end{array}$ & $\begin{array}{l}\text { 5-, } 10-, 35-, 40-, \text { and } 70-\mathrm{mg} \\
\text { tablets; } 70 \mathrm{mg} / 75 \mathrm{~kL} \text { oral solution }\end{array}$ & Yes \\
\hline $\begin{array}{l}\text { Alendronate sodium } \\
\text { plus vitamin } D_{3}\end{array}$ & $\begin{array}{l}\text { Fosamax } \\
\text { Plus D }\end{array}$ & $\begin{array}{l}\text { Merck and Co. Inc., Whitehouse } \\
\text { Station, New Jersey }\end{array}$ & $\begin{array}{l}70-\mathrm{mg} \text { and } 2800-\mathrm{U} \\
\text { cholecalciferol tablet }\end{array}$ & Yes \\
\hline Pamidronate disodium & Aredia & $\begin{array}{l}\text { Novartis Pharmaceuticals, } \\
\text { East Hanover, New Jersey }\end{array}$ & 30-, 60-, and 90-mg vials & Yes \\
\hline Risedronate sodium & Actonel & $\begin{array}{l}\text { Procter and Gamble Pharmaceuticals, } \\
\text { Cincinnati, Ohio }\end{array}$ & 5-, 30-, and 35-mg tablet & Yes \\
\hline $\begin{array}{l}\text { Risedronate sodium } \\
\text { plus calcium }\end{array}$ & $\begin{array}{l}\text { Actonel with } \\
\text { calcium }\end{array}$ & $\begin{array}{l}\text { Procter and Gamble Pharmaceuticals, } \\
\text { Cincinnati, Ohio }\end{array}$ & $\begin{array}{l}\text { 35-mg and } 500-\mathrm{mg} \\
\text { calcium tablets }\end{array}$ & Yes \\
\hline Zoledronic acid & Zometa & $\begin{array}{l}\text { Novartis Pharmaceuticals, } \\
\text { East Hanover, New Jersey }\end{array}$ & 4-mg vial† & Yes \\
\hline Ibandronate sodium & Boniva & $\begin{array}{l}\text { Roche Laboratories Inc., } \\
\text { Nutley, New Jersey }\end{array}$ & $\begin{array}{l}2.5-\mathrm{mg} \text { tablet } 150-\mathrm{mg} \text { tablet3 } \\
\mathrm{mg} / 3 \mathrm{~mL} \dagger\end{array}$ & Yes \\
\hline
\end{tabular}


recruitment of osteoclasts and induce osteoblasts to produce an osteoclast-inhibiting factor. Aminobisphosphonates exert several antitumor effects, including induction of tumor cell apoptosis, inhibition of tumor cell adhesion to the extracellular matrix, and inhibition of tumor invasion. Bisphosphonates also have antiangiogenesis properties and can activate $T$ cells. The use of bisphosphonates in patients with multiple myeloma and metastatic cancer to the bones, such as breast, prostate, lung, and renal cell carcinomas, has resulted in a statistically significant reduction in skeletal complications, including pathologic fractures, spinal cord compression, hypercalcemia of malignant disease, and the need for subsequent radiotherapy or surgery to bone(7-9). Intravenous bisphosphonates have improved bioavailability and do not produce gastrointestinal side effects, resulting in better patient adherence. They have become standard therapy in the management of patients with multiple myeloma and metastatic cancer.

\section{INCIDENCE}

The initial correlation between the use of oral alendronate and ONJ was not statistically significant, with an incidence of 0.7 per 100,000 persons per year of exposure(1). Most reports and experts disagree with this figure. Several recent studies of patients with multiple myeloma and patients with breast cancer who received intravenous aminobisphosphonate therapy for metastatic bone lesions demonstrated $6-11 \%$ of the patients developed bisphosphonate-related osteonecrosis of the jaw (BRONJ) $(10,11)$. Osteonecrosis of the jaws are manifested more commonly in mandible than maxilla. There is a slight female predilection in a ratio of 3:2. Most lesions were on the posterior lingual mandible near the mylohyoid ridge. $60 \%$ of cases occurred after a tooth extraction or other dentoalveolar surgery and the remaining cases occurred spontaneously (12).

\section{SUSCEPTIBILITY OF THE JAWS TO OSTEONECROSIS}

The question often asked is "Why the jaws?" The answer to this is the the jaws have a greater blood supply than other bones and a faster bone turnover rate related both to their daily activity and the presence of teeth (which mandates daily bone remodeling around the periodontal ligament), bisphosphonates are highly concentrated in the jaws (12). Coupled with chronic invasive dental diseases and treatments and the thin mucosa over bone, this anatomic concentration of bisphosphonates causes this condition to be manifested exclusively in the jaws.

\section{RISK FACTORS}

- Advanced patient age (older than 65 years)

- Corticosteroid use

- Use of chemotherapy drugs

- Diabetes

- Smoking or Alcohol use

- Poor oral hygiene

- Duration of drug use exceeding 3 years (13).

\section{PRESENTATION}

Symptoms may include the following:

- Pain

- Swelling

- Cellulitis

- Halitosis

- Trismus

Physical findings may include the following:

- Mandibular and or maxillary bone exposure

- Pathologic fracture

- Oral-cutaneous fistula

- Clinical infection

\section{RADIOGRAPHIC FINDINGS}

Increased radiopacity before clinical evidence of frank necrosis. These changes typically occur predominantly in areas of high bone remodeling such as the alveolar ridges. Panaromic radiographs often will reveal a marked radiodensity of the crestal portions of each jaw with a more normal appearance of the bone away from tooth bearing portions. Periosteal hyperplasia also is not rare. In most severe cases, the osteonecrosis creates a moth eaten and ill defined radioluscency with or without central radiopaque sequestra (13). In some cases the necrosis can lead to development of a cutaneous sinus or pathologic fracture. 


\section{INVESTIGATIONS}

\section{Laboratory Studies}

Rule out a primary malignancy, benign bone lesion, osteomyelitis, or metastatic lesion by biopsy when indicated.

A recent study suggests an increase in serum C-terminal telopeptide (CTX) after a "drug holiday" from oral bisphosphonates may help guide surgical treatment (14). These data have not been corroborated and have not been shown to be reliable. The value of this test is uncertain.

\section{Imaging Studies}

In patients with bisphosphonate-related osteonecrosis of the jaw (BRONJ), panoramic and plain radiography of the mandible reveal areas of sclerosis, destruction, sequestration, or pathologic fractures. Delayed or persistent tooth sockets after extraction may also be revealed in these patients.

A recent study evaluating the computed tomography (CT) and magnetic resonance imaging (MRI) features of bisphosphonate-related osteonecrosis of the jaw (BRONJ) demonstrated characteristic findings with these studies. The CT scans revealed increased medullary density, periosteal reaction, and bone sequestration. MRI revealed a low signal in T1 and T2 images with exposed bone. This is likely due to a decrease in water content. Unexposed, diseased bone showed hypointensity in T1 images and hyperintensity in T2 images. These findings suggest an increase in water content (15).

\section{Diagnostic Procedures}

The following diagnostic procedures may be beneficial in the diagnosis of bisphosphonate-related osteonecrosis of the jaw (BRONJ):

- Panoramic or plain-film imaging

- CT scanning

- MRI

- Area biopsy (if indicated)

\section{Histologic Findlings}

Histologically, nonvital bone that is devoid of osteoblasts and osteoclasts are noted. Fungal contamination of exposed bone has been noted. In affected but unexposed bone, inflammatory infiltrates, fibrous tissue, and a combination of lamellar and woven bone is noted. Viable osteocytes are seen within this bone.

\section{Staging}

The following staging system has been proposed by the American Association of Oral and Maxillofacial Surgeons (AAOMS)(16).

\section{- Stage I}

- Exposed, necrotic bone

- Asymptomatic patient

- No infection

\section{- Stage II}

- Exposed, necrotic bone

- Symptomatic patient (ie, patient experiencing pain)

\section{Infection}

\section{- Stage III}

- Exposed, necrotic bone

- Symptomatic patient (ie, patient experiencing pain)

- Infection

- One of the following:

- Pathologic fracture

- Oral cutaneous fistula

- Osteolysis extending to the inferior border of the mandible

\section{TREATMENT}

\section{Medical Therapy}

Nonsurgical management of bisphosphonate-related osteonecrosis of the jaw (BRONJ) may consist of the following:

- Antimicrobial rinses

- Systemic antibiotics

- Systemic or topical antifungals

- Discontinuation of bisphosphonate therapy

- No dental therapy or minimally invasive dental therapy (ie, root canal therapy instead of extraction)

\section{Surgical Therapy}

Surgical intervention for bisphosphonate-related 
osteonecrosis of the jaw (BRONJ) remains limited because of the impaired ability of the bone to heal. Because no long-term or controlled studies on the management of bisphosphonate-related osteonecrosis of the jaw (BRONJ) have been published, the article from AAOMS, which is based on the consensus of a panel discussion, is the best available guide to therapy (16). The suggested treatment of bisphosphonaterelated osteonecrosis of the jaw (BRONJ) is determined by the patient's classification according to the following stages:

\section{- Stage I}

- Antimicrobial rinses (ie, chlorhexidine 0.12\%)

- No surgical intervention

\section{- Stage II}

- Antimicrobial rinses (ie, chlorhexidine 0.12\%)

- Systemic antibiotics or antifungals (infections may exacerbate BRONJ)

- Analgesics

- Stage III

- Antimicrobial rinses (ie, chlorhexidine 0.12\%)
- Systemic antibiotics or antifungals (infections may exacerbate BRONJ)

- Analgesics

- Surgical debridement or resection

\section{CONCLUSION}

Osteonecrosis of the jaws is a newly recognized condition reported in patients treated with bisphosphonates, in particular potent aminobisphosphonates. Most cases have developed in patients with multiple myeloma or metastatic cancer, but the condition has also been identified in patients with osteoporosis. Long-term data are not available concerning the appropriate management of bisphosphonate-related osteonecrosis of the jaw. Traditional reconstructive efforts are generally not recommended by most experts. The role of adjunctive procedures (ie, hyperbaric oxygen [HBO]) and vascularized tissue transfers in the reconstructive management of bisphosphonate-related osteonecrosis of the jaw have yet to be elucidated. 


\section{REFERENCES}

1. Sedghizadeh PP, Stanley K, Caliguri M, Hofkes S, Lowry B, Shuler CF. Oral biphosphonate use and the prevalence of osteonecrosis of the jaw: An institutional inquiry. J Am Dent Assoc 2009;140:6166.

2. Lee AMP. Dental Side Effects of Oral Bisphosphonates. Drug Review 2008;13(11): 21-22.

3. Zuffetti F, Bianchi F, Volpi R, Trisi P, Del Fabbro M, Capelli M, et al. Clinical application of bisphosphonates in implant dentistry: histomorphometric evaluation. Int J Periodontics Restorative Dent 2009;29(1):31-39.

4. Fleisch H. Bisphosphonates: mechanisms of action. Endocr Rev 1998;19:80-100.

5. Russell RG, Croucher PI, Rogers MJ. Bisphosphonates: pharmacology, mechanisms of action and clinical uses. Osteoporos Int 1999;9(Suppl 2):S66-80.

6. Lin JH, Russell G, Gertz B. Pharmacokinetics of alendronate: an overview. Int $J$ Clin Pract Suppl 1999;101:18-26.

7. Lipton A, Theriault RL, Hortobagyi GN, Simeone J, Knight RD, Mellars K, et al. Pamidronate prevents skeletal complications and is effective palliative treatment in women with breast carcinoma and osteolytic bone metastases: long term follow-up of two randomized, placebo-controlled trials. Cancer 2000;88:1082-1090.

8. Berenson JR, Rosen LS, Howell A, Porter $\mathrm{L}$, Coleman RE, Morley W, et al. Zoledronic acid reduces skeletal-related events in patients with osteolytic metastases. Cancer 2001;91:1191-2000.
9. Saad F. Clinical benefit of zoledronic acid for the prevention of skeletal complications in advanced prostate cancer. Clin Prostate Cancer 2005;4:3137.

10. Bamias A, Kastritis E, Bamia C, et al. Osteonecrosis of the jaw in cancer after treatment with bisphosphonates : incidence and risk factors. $J$ Clin Oncol 2005;23(34):580-587.

11. Mavrokokki T, Cheng A, Stein B, et al. Nature and frequency of bisphosphonate associated osteonecrosis of the jaw. $J$ Rheumatol 2009;36(3):478-90.

12. Marx RE, Sawatari Y, Fortin M, Broumand V. Bisphosphonate-induced exposed bone (osteonecrosis/osteopetrosis) of the jaws: risk factors, recognition, prevention, and treatment. J Oral Maxillofac Surg 2005;63:1567-75.

13. Neville BW, Damm DD, Allen CM, Bouquot JE. Physical and chemical injury. In: Oral and maxillofacial pathology 3rd ed. St. Louis,Missouri: Elsevier Inc. 2009:pp.285-329.

14. Marx RE, Cillo JE Jr, Ulloa JJ. Oral bisphophonate inuced osteonecrosis: risk factors, prediction of risk using serum CTX testing, prevention and treatment. J Oral Maxillofac Surg 2007;65(12): 2397-2410.

15. Bedogni A, Blandamura S, Lokmic Z, et al. Bisphosphonate associated jaw bone osteonecrosis: a correlation between imaging techniques and histopathology. Oral Surg Oral Med Oral Pathol Oral Radiol Endod 2008;105(3):358-364.

16. AAOMS- American Association of Oral and Maxillofacial Surgeons position paper on bisphosphonate related osteonecrosis of the jaws. J Oral Maxillofac Surg 2007;65(3):369-376.

\section{THE AUTHOR}

\section{Dr. Manpreet S Walia MDS (Professor) \\ Professor \& Head \\ Deptt. of Prosthodontics}

Dr. H.S.J. Institute of Dental Sciences and Research, Punjab University,

Chandigarh

\section{Dr. Saryu Arora}

MDS (Senior Lecturer)

Deptt. of Prosthodontics

Shri Sukhmani Dental College and Hospital, Derabassi, Punjab

\section{Dr. Bhawana Singal}

MDS (senior lecturer)

Dept. of Conservative Dentistry and Endodontics

Shri Sukhmani Dental College and Hospital, Derabassi,

Punjab 